\title{
Shear Connection between Steel and Concrete in Composite Structure
}

\author{
Surendar M , Deepak M S
}

\begin{abstract}
For the past few decades, the construction field has been moving towards the usage of steel-concrete composite structural elements in most of its construction. Various research works are carried out to increase the structural aspects of such composite construction. Shear connector between concrete and steel elements in composite construction plays an important role in developing the composite action by ensuring proper shear transfer between the steel profile and the concrete element. The connections between the steel and concrete sections are mostly done using welding, given the durability and strength of welding. For the current study, the shear connectors, connecting the concrete slabs and steel beam, are welded to the flanges of the beam. Given the flexible nature of the shear connectors, they can be available in various shapes and sizes. The performance of each connector was evaluated and compared. The main comparison between the specimens was carried out by comparing the load slip behavior of the specimens.
\end{abstract}

Keywords - Shear connector, Composite action, Channel connector, Welded connection, Load slip behavior.

\section{INTRODUCTION}

In a structural member when two or more materials are used in constructing a single element the connection between those elements plays a major role in all the aspects. The main objective of providing the connection between the different materials in a single element is to make than element to act as a single monolithic element. Then comes the transfer of loads, resisting the loads and other structural properties. These types of construction are in use from the past decades. Started with concrete- iron composites various combinations of composites emerge. Among the types, the mostly used one is concrete-steel composites for the many action and to increase the bond between steel beam and concrete slab, a steel projection named as shear connector have been used. Resistance offered in compression and tension by Concrete and Steel respectively is completely utilized by connecting them properly through Shear connectors. The objective of providing this shear connector is to transfer the loads and to resist the force caused during heavy wind, seismic forces and other shear forces. Since the study on connectors is in progress from past few decades, various types of connectors emerge. Some of them are stud connector, perfobond connector, t-rib connector, channel connector, oscillating connector, I section connector, angle connector etc. These shear connectors are usually welded to the flanges of the beam. Based on the purpose of use,

Revised Manuscript Received on 14 September, 2019.

Surendar M , Assistant Professor, Department of Civil Engineering, Easwari Engineering College (SRM), Chennai 600089 Tamil Nadu, India (Email: m.srndr@gmail.com)

Deepak M. S., Assistant Professor, Department of Civil Engineering, Easwari Engineering College (SRM), Chennai 600089 India(Email: deepakms143@gmail.com) similar properties between them. To increase the monolithic

quality, strength and deformation shear connectors are broadly classified into rigid and flexible shear connectors.

\section{MATERIAL COLLECTION AND TESTING}

The materials required for the project are cement, $\mathrm{M}$ sand and coarse aggregates to produce concrete. The preliminary testing on these materials is done.

A. Properties

- $\quad$ Grade of cement = OPC (53 grade $)$

- $\quad$ Specific gravity of cement $=3.15$

- Normal consistency of cement $=32 \%$

- Initial setting time $=35$ minutes

- $\quad$ Final setting time $=450$ minutes

- $\quad$ Fineness of cement $=6 \%$

- $\quad$ Specific gravity of M. Sand $=2.68$

- $\quad$ Fineness modulus of M. Sand $=3.07$

- $\quad$ Specific gravity of coarse aggregate $=2.68$

B. Mix ratio

The grade of concrete chosen is M-30.The mix ratio for M-30 grade is designed as per IS10262:1982. The mix is designed as normal mix without using any plasticizers or admixtures. The mix ratio is given as

Cement: Fine Aggregate: Coarse Aggregate:

$w / c=1: 1.726: 2.70 / 0.45$

C. Fresh concrete test:

- $\quad$ Slump value: $54 \mathrm{~mm}$

- $\quad$ Compaction factor : 0.911

- $\quad$ Flow table value: $38.9 \%$

D. Mechanical properties of concrete

Table I Mechanical Properties

\begin{tabular}{|l|l|l|}
\hline Sl. No. & Property & Result \\
\hline 1 & Ultrasonic pulse velocity & $5056 \mathrm{~m} / \mathrm{s}$ \\
\hline 2 & Compressive strength & $42.71 \mathrm{MPa}$ \\
\hline 3 & Flexural strength & $5.46 \mathrm{MPa}$ \\
\hline 4 & Split tensile strength & $5.06 \mathrm{MPa}$ \\
\hline
\end{tabular}

Note: The above values are average of 3 tests of specimens.

Published By: 


\section{E. $\quad$ Stress strain behavior of M-30 Grade Concrete}

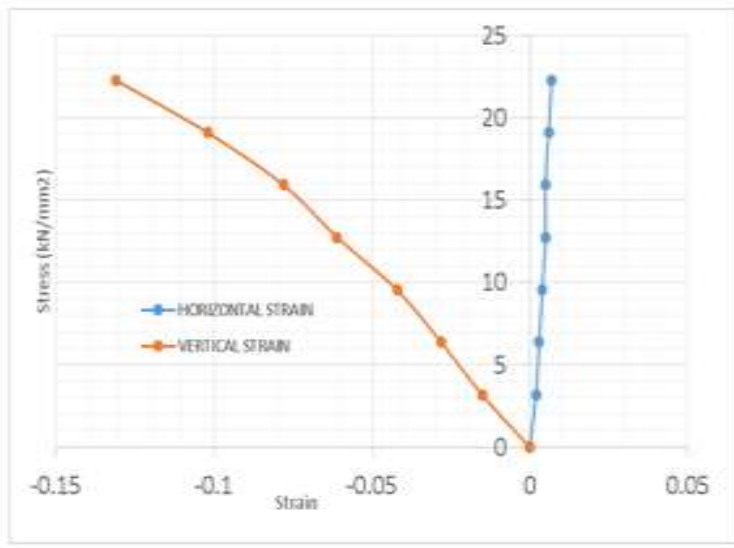

\section{EXPERIMENTAL PROGRAM:}

A. Properties of beam:

- $\quad$ Beam : ISMB100

- Weight per $\mathrm{m}: 8.0 \mathrm{~kg}$

- Sectional area : $10.21 \mathrm{~cm}^{2}$

- Depth of section : $100 \mathrm{~mm}$

- Width of flange : $50 \mathrm{~mm}$

- $\quad$ Thickness of flange : $6.4 \mathrm{~mm}$

- Thickness of web : $4 \mathrm{~mm}$

B. Properties of shear connector

In this project, channel section is used as shear connector.

- $\quad$ Connector : ISMC 75

- Weight per $\mathrm{m}: 6.8 \mathrm{~kg}$

- $\quad$ Sectional area : $8.67 \mathrm{~cm}^{2}$

- Depth of section : $75 \mathrm{~mm}$

- Width of flange : $40 \mathrm{~mm}$

- $\quad$ Thickness of flange : $7.3 \mathrm{~mm}$

- $\quad$ Thickness of web : $4.4 \mathrm{~mm}$

C. Properties of slab:

- Length

: $300 \mathrm{~mm}$

- Thickness

$100 \mathrm{~mm}$

- Height : $360 \mathrm{~mm}$

- Cover : $20 \mathrm{~mm}$

$8 \mathrm{~mm}$ diameter rod is provided at $80 \mathrm{~mm}$ center to Center spacing is provided as Nominal reinforcement. The longitudinal bars are bended towards the connector.

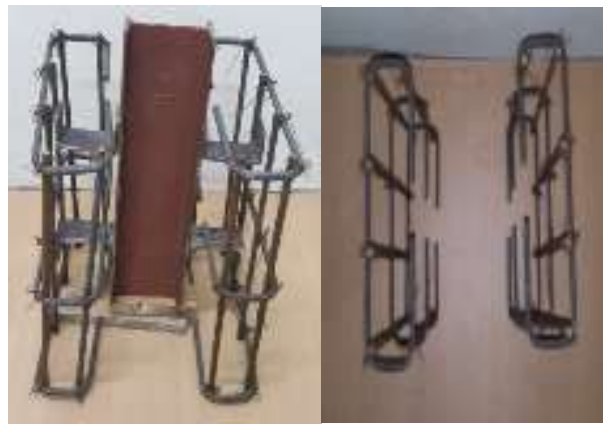

Fig. 2: Reinforcement cage

\section{Fabrication, casting and curing}

In this structural element, the steel shear connector is welded to the flanges of the steel beam at the specified position. There are two types of specimens. One specimen is cast with a single shear connector and the other specimen is cast with two shear connector. And then the reinforced slab is casted on the side of the flanges. While casting the beam is raised $40 \mathrm{~mm}$ above the base of the slab. It is so because while applying load, it should not directly applied on the slab. The specimen is cast using M30 grade concrete. The hand mix concrete is made and is poured in the mould and compacted using tamping rod. The wet gunny bag curing was adopted. In the specimen with single connector, the connector is welded at the center of the beam. In specimen with double connector, the connector is welded at $60 \mathrm{~mm}$ offset from the center. One connector is placed at $60 \mathrm{~mm}$ above the center and another one $60 \mathrm{~mm}$ below the center. The fabrication details are given in Fig.2 \& Fig.3.

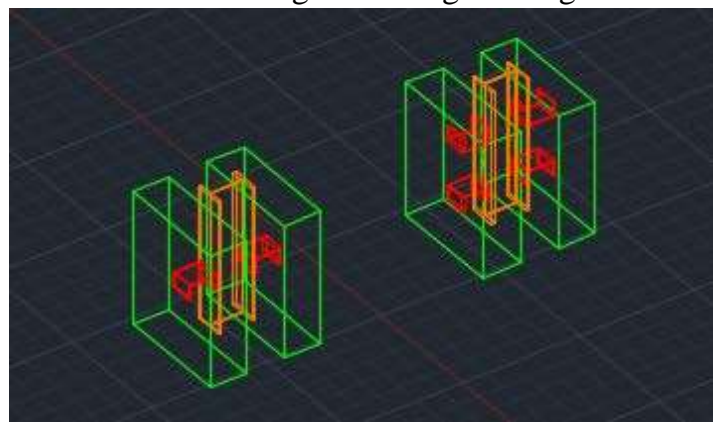

Fig. 3: Fabrication diagram
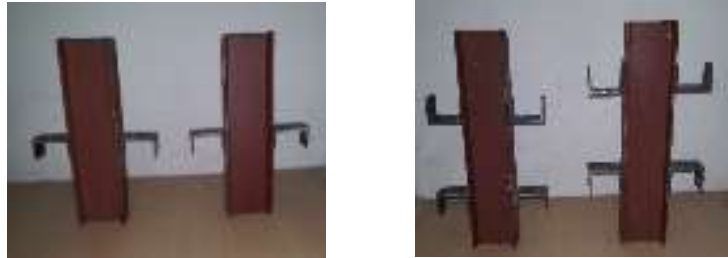

Fig. 4 Beam with Connectors

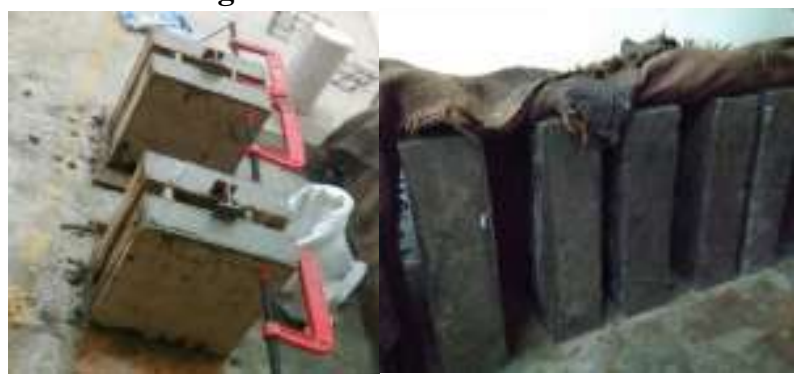

Fig. 5: Casting and Curing

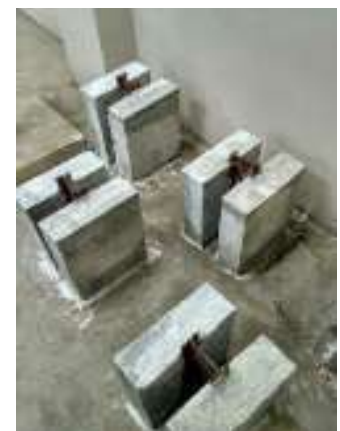

Fig. 6: Finished speciment after curing

\section{E. Specimen}

Two type specimens (each two) are cast by placing

Published By 
connectors at different position on the flange of the beam. In one specimen static loading is given and in another dynamic loading is given. The specimen description is given is Table 6.

\section{F. $\quad$ Test Procedure}

While testing, the compressive load is applied on the web of the beam using UTM. The vertical strain in the beam is measured using an electrical strain gauge pasted on the edge mid of the web. The vertical strain, horizontal strain at middle and top of the slab is measured using a demec gauge. The stain is measured only on one side of the slab. UPV test is conducted on the top of the slab, to measure the micro cracks. The slip is measured using dial gauge with $0.01 \mathrm{~mm}$ least count for each corresponding load. The overall experimental setup is given in Fig.7 and the position of demec gauge pellets in slab and electrical strain gauge in beam is given in Fig.8.

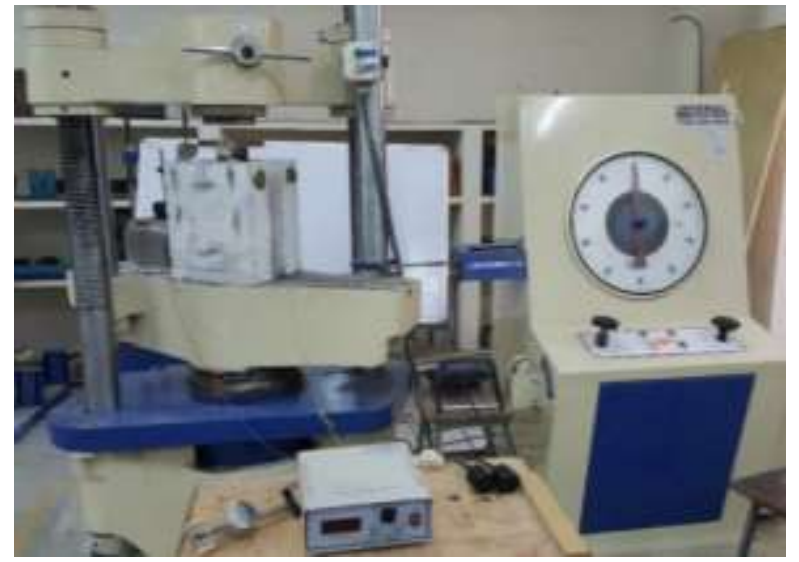

Fig. 7: Experimental Set-up

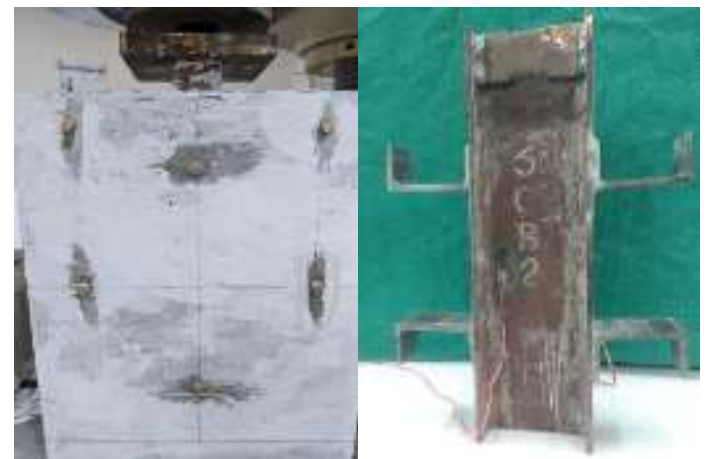

Fig. 8: Position of demec gauge pellets in slab and electrical strain gauge in beam

\section{TEST OBSERVATIONS \& RESULTS}

\section{A. Specimen ID: SCAI Observation}

First crack started at 225KN.The Crack developed near the I-section and slowly propagated to the edge of the slab (top surface).The failure of shear connector occurred at the load of $275 \mathrm{KN}$. The failure occurred at the welded portion (one side). Fig.14 shows that, after $275 \mathrm{kN}$, the load starts released and the slip value goes on increasing. Crack width increase slowly at the inner surface of the both slab. Symmetrical crack develop on both slab. The crack pattern is shown in Fig.9. The connector, lifted upwards by $8 \mathrm{~mm}$ and at the ultimate load, the connector failed at the welded portion. From Fig.20, it is obtained that for the same load, the horizontal strain is small in middle when compared to top in the slab. This is because of the presence of the shear connector near the mid of the slab. From Fig.16 and Fig.18 it is obtained that the vertical strain is slab and beam increases linearly with load.
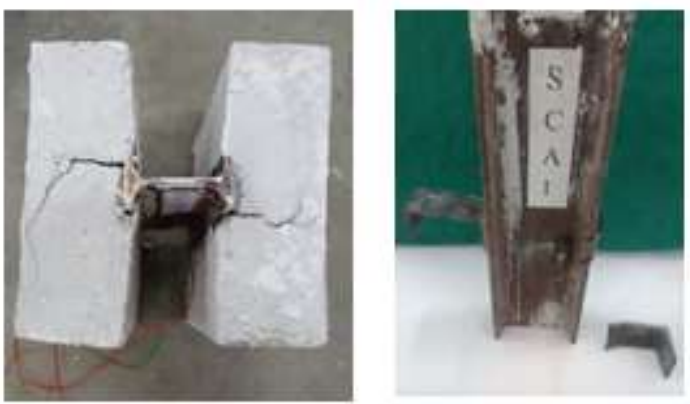

Fig. 9: Specimen ID: SCA1 after testing

Table II Specimen description

\begin{tabular}{|l|l|l|}
\hline Specimen ID & Description Image \\
\hline SCA1 & $\begin{array}{l}\text { Static load test on } \\
\text { Specimen with one } \\
\text { shear connector }\end{array}$ \\
\hline SCA2 & $\begin{array}{l}\text { Static load test on } \\
\text { Specimen with two } \\
\text { shear connector }\end{array}$ \\
\hline SCB1 & $\begin{array}{l}\text { Cyclic load test on } \\
\text { Specimen with one } \\
\text { shear connector }\end{array}$ \\
\hline SCB2 & $\begin{array}{l}\text { Cyclic load test on } \\
\text { Specimen with two } \\
\text { shear connector }\end{array}$ \\
\hline
\end{tabular}

\section{B. Specimen ID: SCA2 Observation:}

Micro crack develops on the top surface. The crack started from inside to outside. It travelled up to center of the slab (on top surface). . The crack pattern is shown in Fig.10.The I section starts buckling at $400 \mathrm{kN}$. Since I section buckled, load not transferred to the slab. The top connector in the left side of the flange lifted upwards by $3 \mathrm{~mm}$ and in the connector in the right side of the slab lifted upwards by $2 \mathrm{~mm}$. The bottom connector in the left side of the flange lifted downwards by $1 \mathrm{~mm}$ and in the connector in the right side of the slab lifted downwards by $2 \mathrm{~mm}$. The connector spacing increased by $4 \mathrm{~mm}$ on both sides of the flange. The buckled portion of specimen is given Fig. 11 . From Fig.20, it is obtained that for the same load, the strain is maximum in the middle and minimum in the top of the slab. The vertical strain is slab and beam increases linearly

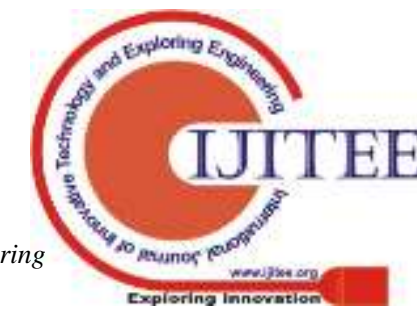


with load. The vertical strain of the specimen is given in Fig.16.From Fig.14, it is obtained that up to $400 \mathrm{kN}$, the slip increases slowly. After I section starts buckling, the slip value increases by large amount for each successive loading. Initially the stain in beam increases by large value. After I section starts buckling, the strain value increases by small amount.

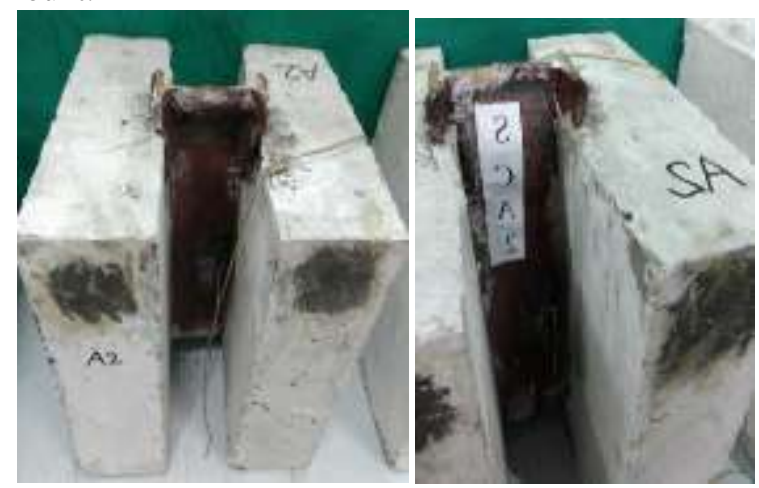

Fig. 10: Specimen SCA2 after testing

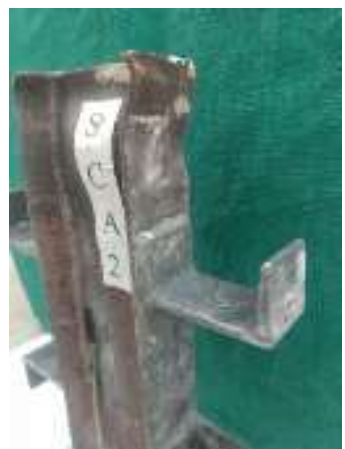

Fig. 11: The buckled portion of SCA2

\section{Specimen ID: SCB1 Observation}

The ultimate load for the same type of element in static loading condition is $275 \mathrm{kN}$. Therefore the cyclic range is chosen as $0-150 \mathrm{kN}$. After 5 cycles, the load increases up to ultimate.

Crack on the top surface of the slab. In outside surface of the slab 2 cracks starts from bottom and travelled towards top. No crack or bend in the beam. The edge of the channel connector lifted upwards by $5 \mathrm{~mm}$ on both sides. The tested specimen is given in Fig.12.From Fig.15, it is obtained that the slip value increases in successive cycle.

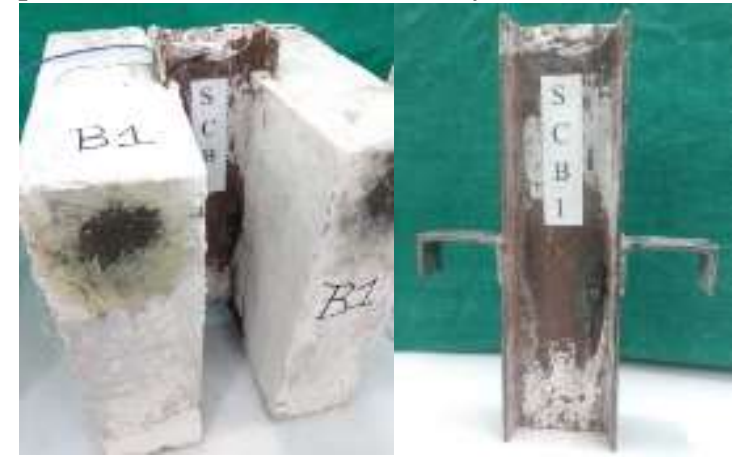

Fig. 12: Specimen SCB1 after testing

\section{Specimen ID: SCB2 Observation}

The ultimate load for the same type of element in static loading condition is $500 \mathrm{kN}$. Therefore the cyclic range is chosen as $0-250 \mathrm{kN}$. After 5 cycles, the load increases up to ultimate. Since the same type of specimen in static loading buckles at the top of the beam, the stiffener is provided on the top of the beam up to $40 \mathrm{~mm}$ depth.

Crack on top surface. It is a through crack. Slab bends outwards. No crack on outside surface. Beam buckles at 500 $\mathrm{KN}$ (ultimate load). The tested specimen is given in Fig.13. From Fig.21, it is obtained that the horizontal strain in the mid of the slab is higher than the strain in the top of the slab. The top connector lifted upwards and the bottom connector bended downwards. The top connector in the left side of the flange lifted upwards by $5 \mathrm{~mm}$ and in the connector in the right side of the slab deflected upwards by $2 \mathrm{~mm}$. The bottom connector in the left side of the flange lifted upwards by $2 \mathrm{~mm}$ and in the connector in the right side of the lifted upwards by $5 \mathrm{~mm}$. The connector spacing increased by $3 \mathrm{~mm}$ on both sides of the flange.
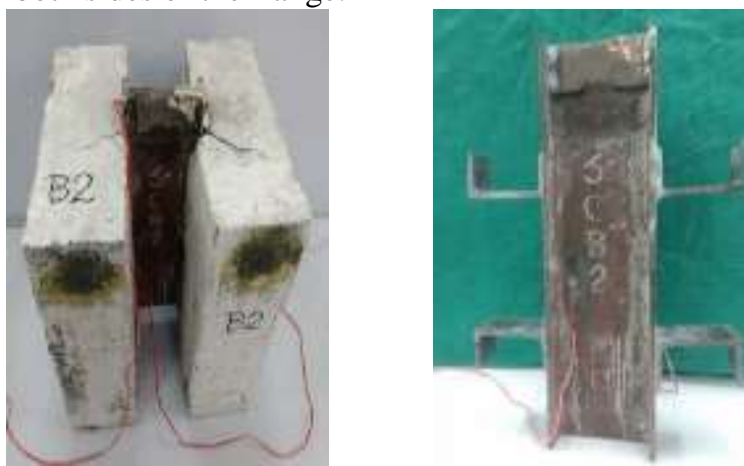

Fig. 13: Specimen SCB2 after testing

\section{RESULTS AND DISCUSSIONS}

On comparison of specimens SC1 and SC2 the following points are discussed

\section{A. Load slip behavior}

The shape of load- slip curve is similar irrespective of number of connector in it. The only difference is the specimen with double connector bears more load than specimen with single connector. The ultimate load for single connector is $275 \mathrm{kN}$ and that for double connector is $500 \mathrm{kN}$ in static loading condition. The result of the load slip is represented in Fig. 14 \& 15.

\section{B. Vertical strain in slab}

The vertical strain in slab is maximum in the specimen with single connector than double connector. The shape of the curve is similar in both the specimens during both static and cyclic loading. The slab undergoes tension in vertical direction during loading. The result of the vertical strain in slab is represented in Fig. 16 \& 17.

\section{Vertical strain in beam}

The vertical strain is a maximum in the specimen with single connector. The shape of the curve is similar in both the specimens in both loading conditions. The result of the vertical strain in beam is represented in Fig. 18 \& 19 . 


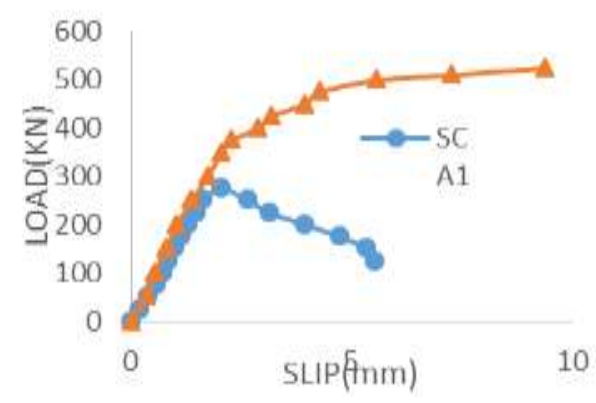

Fig. 14: Load vs slip of SCA1 \&SCA2

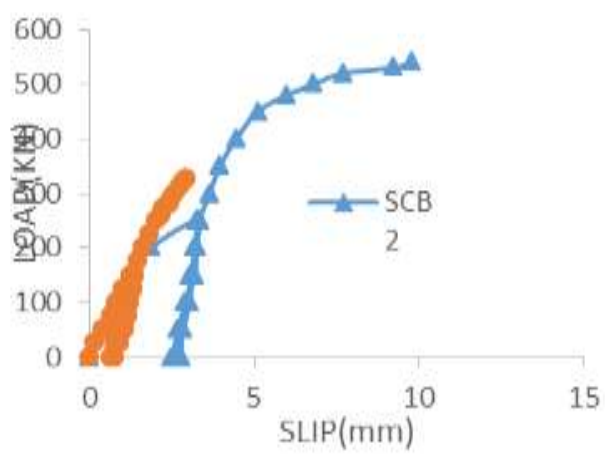

Fig. 15: Load vs slip of SCA1 \&SCA2

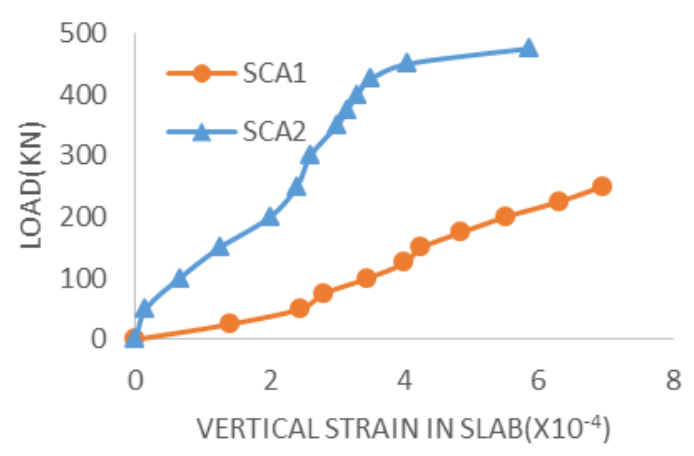

Fig. 16: Load vs. vertical strain of SCA1\& SCA2

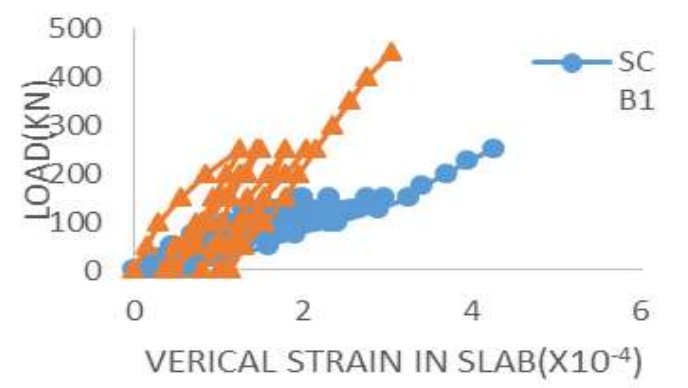

Fig. 17: Load vs. vertical strain of SCB1\& SCB2

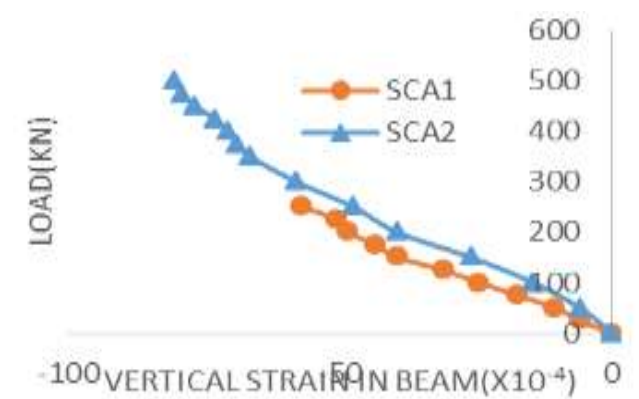

Fig. 18: Load vs vertical strain in beam of SCA1\& SCA2

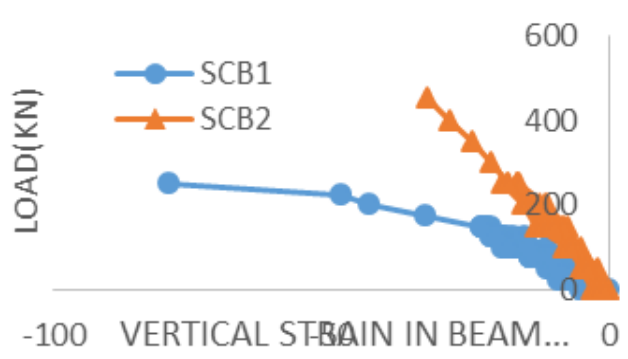

Fig. 19: Load vs vertical strain in beam of SCB1\& SCB2

\section{Horizontal strain in slab}

The horizontal strain in top of the slab is a maximum in specimen with single connector. This is because of the location of the shear connector. Since one of the connector in SCA2 \& SCB2 is placed near the top of the beam, the strain is a minimum in the top of slab. The horizontal strain in middle of the slab is vice versa to the horizontal strain in top of the slab. The horizontal strain in middle of the slab is a maximum in the specimen with two connectors. The result of the horizontal strain in slab is represented in Fig. 20 \& 21.

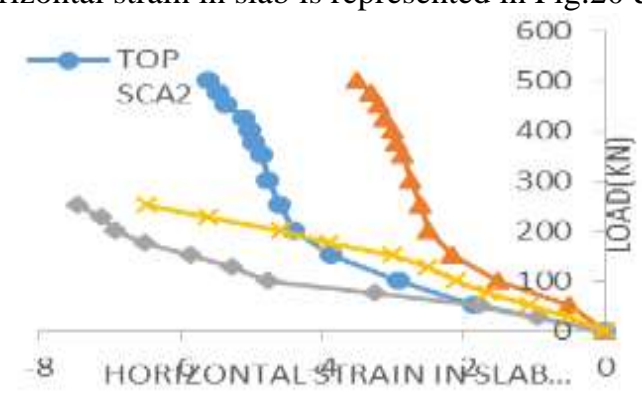

Fig. 20: Load vs horizontal strain of SCA1\& SCA2

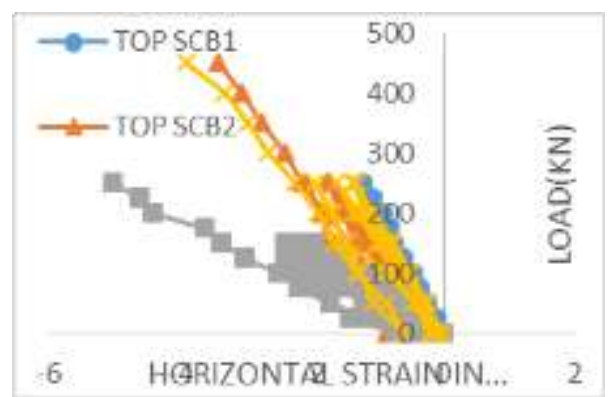

Fig. 21: Load vs. horizontal strain of SCB1\& SCB2 Residual slip at Zero Load

In SCB1 the slip increases in each cycle, this implies that the slip is recovered in each cycle. In SCB2, the slip doesn't recover in each successive cycle.

Table III Residual Slip at Zero Load

\begin{tabular}{|c|cc|c|}
\hline Cycle & $\begin{array}{c}\text { Slip } \\
\text { SCB1(mm) }\end{array}$ & of & $\begin{array}{c}\text { Slip } \\
\text { SCB2(mm) }\end{array}$ \\
\hline 1 & 0 & 0 \\
\hline 2 & 0.64 & 2.65 \\
\hline 3 & 0.67 & 2.5 \\
\hline 4 & 0.69 & 2.78 \\
\hline 5 & 0.73 & 2.55 \\
\hline 6 & 0.75 & 2.54 \\
\hline
\end{tabular}

Published By: 


\section{CONCLUSION}

The specimens with two different locations of shear connector were casted and tested. From the test results the following conclusions are arrived.In this experimental programmee two different types of failures are observed.

- $\quad$ Failure of the channel connector

- Crushing-spalling of concrete

The specimen SCA1 alone failed due to failure of the channel connector at the extreme load, the channel connector at one side of the slab gets detached from the beam. The failure occurred at the welded portion of the connector. The specimens SCB1, SCA2 \&SCB2 undergone crushing splitting of concrete.

- $\quad$ The number of connector decides the load bearing capacity of the specimen. The specimen with two number of connectors bears a large load than a specimen with a single connector.

The strain in slab is infulenced by the position of connector. The middle horizontal strain in slab is minimum in SCA1 \&SCB1. This is because the connector is positioned near the mid of the slab.

- The horizontal strain in top of the slab is maximum is SCA1 \&SCB1. This is beacuase the strain is meassured at a distance away from the connector.

The maximal and minimal horizontal strain in SCA2 \& SCB2 is viceversa of SCA1 \&SCB1.

- In the specimens SCA2 \& SCB2, the beam gets buckled. This is because, the connector is strong to transfer the load, but the top portion of the beam unable to bear the laod. This buckling can be reduced by providing a stiffener.

Almost in all the specimens the connector lifted upwards or bended downwards to some extend, this can be reduced by providing a stiffener in the connector or by increasing the thickness of the connector.

- From the results obtained, the position of the connector, the number of connector, the thickness of connector, the extra provisions like stiffeners in beam are the factors which influence the load carrying capacity of the

\section{ACKNOWLEDGEMENT}

We are extending our sincere thanks to our Professor Dr. M. Neelamegam of Easwari Engineering College and our beloved students Neru Prasad V K, Abirajan J, Arjun Ramasamy M for their direct and indirect support.

\section{REFERENCES}

1. Hiroto hoshina, chikako Fujiyama, "Performance of headed stud on steel-concrete composite bridge deck as shear connector subjected to normal force", Procedia engineering 171 (2017) 1294-1300.

2. [2] Raj PV, Sathiya Bama P, "An analytical and experimental investigation of shear connectors in composite section", International Research Journal of Engineering and Technology (IRJET) Volume: 04 Issue: 06 | June-2017 www.irjet.net, e-ISSN: 2395 -0056, pISSN: 2395-0072.

3. Anju. T, Smitha. K .K, "Finite element analysis of composite beam with shear connectors", Procedia Technology 24 (2016) $179-187$ specimen.

4. Pankaj Kumara, Sandeep Chaudharya, Rajesh Guptaa, "Behavior of adhesive bonded and mechanically connected steel concrete composite under impact loading", 11th International Symposium on Plasticity and Impact Mechanics, Implast 2016.

5. S. Dhanush, K. Balakrishna Rao, "Flexural behavior of segmental composite skew slabs with truss shear connector", International Journal of Scientific Research Engineering \& Technology (IJSRET), ISSN 2278 0882Volume 4, Issue 3, March 2015.

6. Kun-Soo Kim, Sang-Hyo Kim, Min-Kyu Lee and Sejun Park, "Residual strength of Y type perfobond rib shear connectors to cycle load on highway bridge",The 2015 world congress on advances in structural engineering and mechanics (ASEM15) Incheon, korea, august 25-29, 2015.

7. David Leaf and Jeffrey A Laman, "Testing and analysis of composite steel-concrete beam flexural strength", ISSN 2319 - 6009 www.ijscer.comVol. 2, No. 3, August 2013@ 2013 IJSCER.

8. Ali Shariati, N. H. RamliSulong, MeldiSuhatril and Mahdi Shariati, "Various types of shear connectors in composite structures: A review", International Journal of Physical Sciences Vol. 7(22), pp. 2876-2890, 9 June, 2012 Available online at http://www.academicjournals.org/IJPS DOI: 10.5897/IJPSX11.004 ISSN $1992 \quad-1950 \quad$ C2012 Academic Journals.

9. S.O.Bamaga, M.M.Tahir, C.S.Tan, "Push test on innovative shear connector for Composite beam with cold-formed steel section", (2012) - 21st International Specialty Conference on Cold-Formed Steel Structures.

10. A. Bouchaira, J. Bujnakb, P. Duratnaa,b and A. Lachalc, "Modelling of the steel concrete pushout test",Procedia Engineering 40 ( 2012 ) $102-107$.

11. Isabel valente, Paulo J.S., Cruz, "Experimental characterization of shear connectors for steel and concrete composite bridge decks", 7th international conference on steel bridges.

12. Minhaj majeed, Pankaj kumar, sandeep chaudhary, "shear stud connectors in steel concrete composites: a review"

13. Sara B.Medberry and Bahram .Shahrooz, "Perfobond shear connector for composite Construction", Engineering journal / first quarter/ 2002

14. Amit pashan, "Behavior of channel shear connectors push out tests", A Thesis Submitted to the Faculty of Graduate Studies and Research in Partial Fulfillment of the Requirements for the Degree of Master of Science in the Department of Civil and Geological Engineering University of Saskatchewan.

15. P. Sai Shraddha, C. Sudha and Dr. M. Lakshmipathy "Study on ductility behavior of different types of shear connectors in composite structural elements", http://www.iaeme.com/IJCIET/index.asp

16. Dr.Mustafa B.Dawood and Dhurgham H.Al-saffar, "Flexural behavior of steel concrete composite beam with web openings and strengthened by CFRP Laminates", XIII International Conference on Computational Plasticity.

17. Akshay A. Thakare, Kalyani V. Kothavade, P. D. Dhake, P. D. Jadhao , "Comparative experimental study on flexural behavior of composite slab and RCC slab", IJRET: International Journal of Research in Engineering and Technology eISSN: 2319-1163 |pISSN: 2321-7308. 
18. Dipl.-Ing. Eberhard Pelke, Dr.-Ing. Karl-Eugen Kurrer, "On the evolution of steel-concrete composite construction", 5th International Congress on Construction History

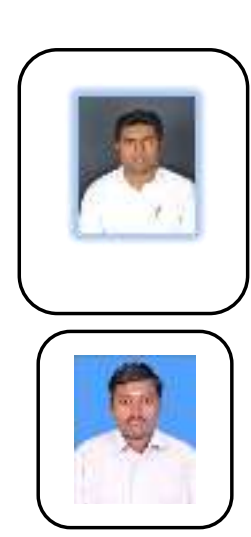

\section{AUTHORS PROFILE}

Deepak M. S., M.E., (Ph.D) in Structural Engineering has 4 years of teaching experience, 6 years of each research and industrial experience, 8 publications, AMIE, AIIV, C. Engg. (I) Government Approved Structural Stability Engineer Class-1A.

Surendar M., M.E., in Structural Engineering has 7 years of teaching experience, 6 years of industrial experience, 8 publications, AMIE. 